\title{
Efficient display of Aspergillus niger $\beta$ - glucosidase on Saccharomyces cerevisiae cell wall for aroma enhancement in wine
}

Yang Zhang, Zhuo Min, Yi Qin, Dong-Qing Ye, Yu-Yang Song*, Yan-Lin Liu*

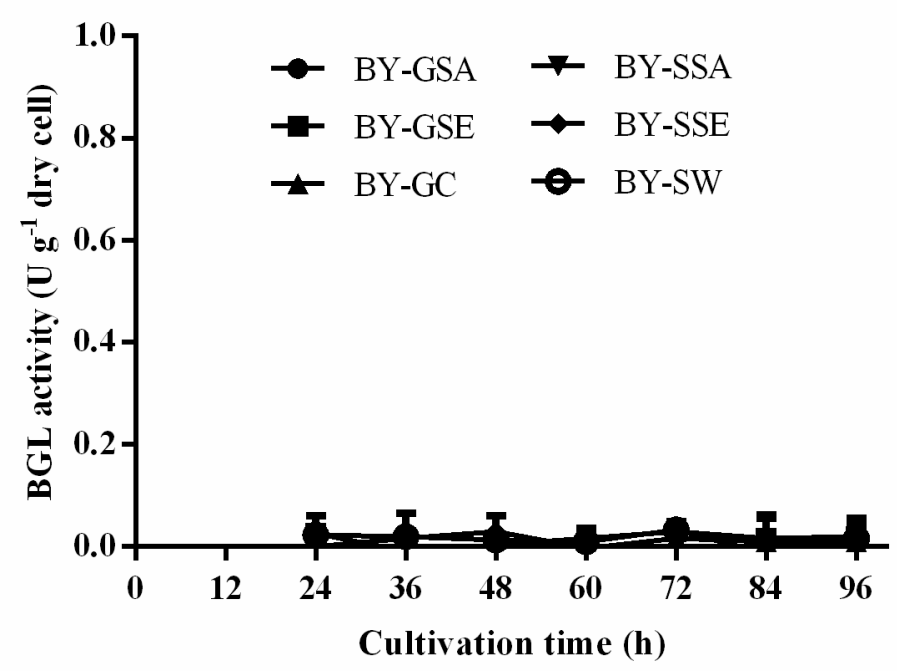

Figure S1. Time course of cell-surface displayed BGL activities in the culture supernatants.

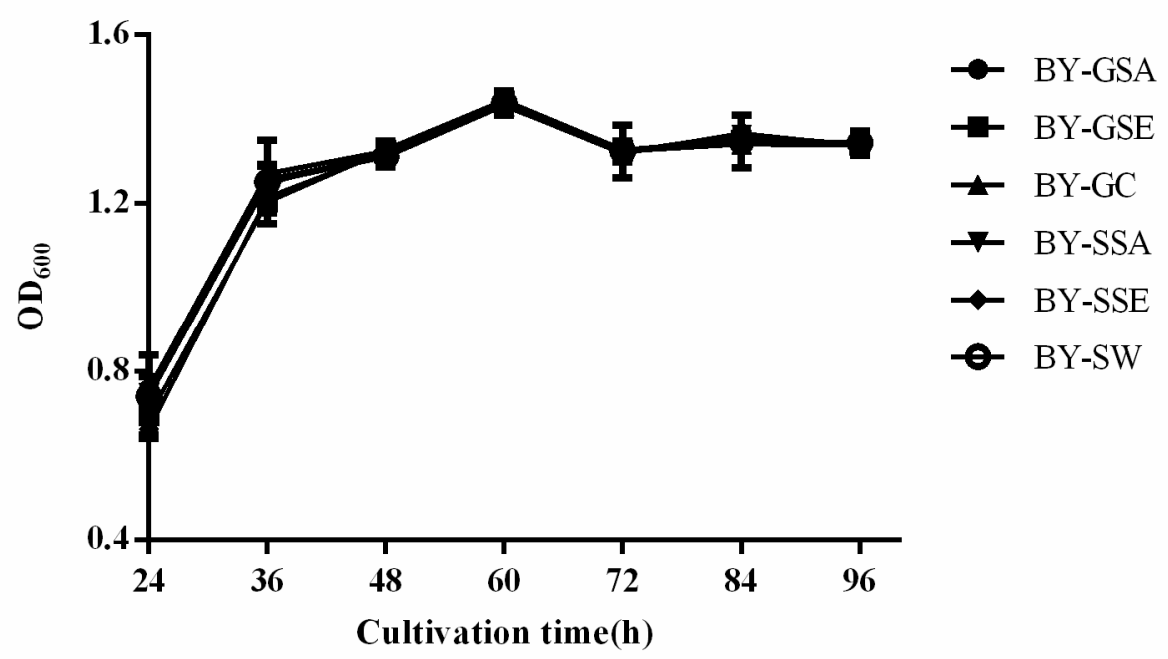

Figure S2. The cell growth of different strains. 